\section{Fluids for Enhanced Geothermal Systems}

Fernandez $z^{1 *}$

Authors: Hongbo Shao, ${ }^{1}$ Senthil Kabilan, ${ }^{1}$ Sean Stephens, ${ }^{1}$ Niraj Suresh, ${ }^{1}$ Anthon N. Beck, ${ }^{1}$ Tamas Varga, ${ }^{1}$ Paul F. Martin, ${ }^{1}$ Andrew Kuprat, ${ }^{1}$ Hun Bok Jung, ${ }^{1}$ Wooyong Um, ${ }^{1}$ Alain Bonneville, ${ }^{1}$ David J. Heldebrant, ${ }^{1}$ Kenneth C. Carroll, ${ }^{2}$ Joseph Moore ${ }^{3}$ and Carlos A.

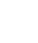

\title{
Environmentally Friendly, Rheoreversible, Hydraulic-Fracturing
}




\section{Abstract}

18 Cost-effective creation of high-permeability reservoirs inside deep crystalline bedrock is the primary challenge for the feasibility of enhanced geothermal systems (EGS). Current reservoir

20 stimulation entails adverse environmental impacts and substantial economic costs due to the

21 utilization of large volumes of water "doped" with chemicals including rheology modifiers, scale

22 and corrosion inhibitors, biocides, friction reducers among others where, typically, little or no

23 information of composition and toxicity is disclosed. An environmentally benign, $\mathrm{CO}_{2}$-activated,

24 rheoreversible fracturing fluid has recently been developed that significantly enhances rock

25 permeability at effective stress considerably lower than current technology based on laboratory-

26 scale tests. In the present work we evaluate the potential of this novel fracturing fluid for

27 application at geothermal sites under different chemical and geomechanical conditions, by

28 performing laboratory-scale fracturing experiments with different rock sources under different

29 confining pressures, temperatures, and $\mathrm{pH}$ environments. The results demonstrate that $\mathrm{CO}_{2^{-}}$

30 reactive aqueous solutions of environmentally amenable Polyallylamine (PAA) represent a

31 highly versatile fracturing fluid technology. This fracturing fluid consistently and reproducibly

32 creates/propagates fracture networks through highly impermeable crystalline rock from Coso

33 EGS and Newberry EGS sites at significantly lower effective stress as compared to conventional

34 fracturing fluids. In addition, permeability was significantly enhanced (several orders of

35 magnitude). This was evident in all laboratory-scale experiments, including variable rock

36 source/type, operation pressure and temperature (over the entire range for EGS applications), as

37 well as over a wide range of formation-water $\mathrm{pH}$ values. This effective, versatile, and

38 environmentally- friendly fracturing fluid technology represents a significant advancement 
39 compared to industrially available fracturing fluids for cost-effective and competitive geothermal 40 energy production.

41

42 Keywords: Environmentally-friendly, rheoreversible, fracturing fluid, expansion, enhanced

43 geothermal systems

44

45

46 


\section{Introduction}

Enhanced geothermal systems (EGS) are considered a p romising alternative for energy production for the United States and worldwide. ${ }^{1,2}$ With its negligible $\mathrm{CO}_{2}$ emissions, EGS can help to mitigate climate change. However, this renewable energy alternative faces challenges. To our knowledge, no prior EGS project has sustained production at rates greater than $50 \%$ of what is needed for economic viability. ${ }^{2}$ The primary limitation for commercial EGS is the lacking of suitable technologies to cost-effectively create high-permeability reservoirs from impermeable crystalline rock within the $900-4000 \mathrm{~m}$ depth in a temperature range of $150-400{ }^{\circ} \mathrm{C} .^{2,3}$

Recent advances in hydraulic fracturing techniques and horizontal drilling represent a key driver for EGS and subsurface energy development, in general. As conventionally recoverable resources decline, hydraulic fracturing in unconventional oil and gas exploitation has been implemented in over 52,000 oil and gas wells across the U.S. ${ }^{4-6}$ However, the fracturing fluids used in the oil and gas industry are problematic for EGS. First, the macropolymers developed to modify fluid rheology in oil/gas standard hydraulic fracturing may not be applicable at geothermal temperature ranges $\left(150-400^{\circ} \mathrm{C}\right)$ due to their thermal decay. ${ }^{7-9}$ Second, these macropolymers are difficult to remove from the formation after fracture creation. The so called "fracture skin", which is the residue of injected polymers and drilling mud not removed during fracture cleanup, limits effectiveness of hydraulic fracturing, because it decreases flow rates and heat transfer in EGS. There is also increasing concern over induced seismicity potential and how it may be associated with reservoir stimulation practices. ${ }^{6,10}$ In addition, the most challenging issue is the large volumes of water used and wastewater generated during hydraulic fracturing that must be treated and disposed of. Finally, the contamination of soil and drinking water 
69 resources have raised both environmental and economic concerns. ${ }^{10}$ Thus, to address these issues 70 and advance the economic viability of EGS, the development of effective and environment71 friendly hydraulic fracturing fluids is needed.

72 We recently developed a new fracturing fluid that can mediate a stimulated expansion 73 and provide a controllable increase of hydraulic pressure to aid in fracturing processes. ${ }^{11}$

74 Triggered by reaction with $\mathrm{CO}_{2}$, this novel fracturing fluid [poly(allylamine) aqueous solution, 75 referred as PAA hereafter] can undergo chemically-induced reactions to form a hydrogel with 76 concomitant large and rapid volume expansion and viscosity increase (Fig. S1 in supporting 77 information). ${ }^{11}$ We reported that in the presence of $\mathrm{CO}_{2}$ under $135 \mathrm{~atm}$ and $190{ }^{\circ} \mathrm{C}$ (the 78 maximum temperature and pressure attained by the instrument), the viscosity of PAA solution 79 was $15 \mathrm{cP}$, as compared a $1-2 \mathrm{cP}$ on the control experiment under identical conditions. ${ }^{11}$

80 Although a comprehensive study on the fracturing mechanism is planned and will be the subject

81 of a coming publication, the authors believe that the volume expansion would generate a

82 significantly increased mechanical stress in the confined environments of the fracture networks 83 propagating fractures at effective stress significantly lower than currently used methods. The goal of the present study is to demonstrate the versatility of this novel fracturing 85 fluid for fracture creation/propagation under different EGS-relevant conditions. Specifically, this work: (1) conducted hydraulic fracturing experiments on rock cores collected from two EGS

87 sites at different pressure, temperatures, and formation fluid $\mathrm{pH},(2)$ characterized the fracture networks and determine overall permeability and (3) performed computational fluid dynamics modeling on two representative EGS rock cores to evaluate the spatial distribution of the fracture 90 networks and compute individual fractures permeabilities as well as bulk post-fracturing 
91 permeability. This work provides qualitative and quantitative basis for the potential application

92 of our new fracturing technology in EGS operations to advance sustainable EGS-based energy

93 production.

\section{2. Materials and Methods}

\section{$95 \quad 2.1$ Chemicals and rock samples}

Poly(allylamine) solution (average MW $\sim 17,000,20 \mathrm{wt} \%$ in $\mathrm{H}_{2} \mathrm{O}$ ) was obtained from Sigma

97 Aldrich. This polymer solution was diluted with deionized water (DIW) for 20 times and the

98 diluted solutions were used for hydraulic fracturing experiments as described below. In some

99 experiments, $\mathrm{pH} 7$ and $\mathrm{pH} 10$ buffer solution (Sigma-Aldrich) was used for sample preparation

100 to characterize the effect of reservoir fluid $\mathrm{pH}$ on the ability of the PAA-based fracturing fluid to

101 create/propagate fractures.

There were two rock cores used in this work. One was collected from the Coso

103 geothermal field in California at depth of $490 \mathrm{~m}$. Coso Rock samples consisted of Mesozoic

104 diorite metamorphosed to greenschist facies. The second rock cores were obtained from

105 Newberry Crater, Oregon, at depth $706 \mathrm{~m}$. These samples consist of siliceous volcanic rocks

106 formed from massive to very vesicular lava flows, pumice, lahars, vitrophyre, cinders, lithic tuff,

107 and interflow breccia. These raw sample materials were cut into small cylindrical rock cores

108 (1.59 $\mathrm{cm}$ diameter and $5.08 \mathrm{~cm}$ length) and a centered hole $(0.32 \mathrm{~cm}$ diameter and $2.54 \mathrm{~cm}$ deep $)$

109 was drilled from the top of the cylinder. The top and bottom of the cores were polished to ensure 110 the sealing with an O-ring (see next section). 


\subsection{Hydraulic fracturing experiments}

Laboratory-scale hydraulic fracturing experiments were performed using the rock cores prepared from rock samples collected from the aforementioned two field sites. A schematic diagram for the hydraulic fracturing experimental setup is shown in Fig. 1. Each rock core was placed in a state-of-the-art cradle designed to expose the entire sample to the desired confining pressure while isolating the central hole drilled to introduce the fracturing fluid (Fig. S2).

Fig. 1. Schematic diagram for the hydraulic fracturing experimental setup.

Stainless steel tubing $(0.16 \mathrm{~cm}$ OD) was introduced $0.5 \mathrm{~cm}$ into the hole leaving an internal dead volume of $\sim 200 \mu \mathrm{L}$ in the rock core. Teflon O-ring was used on the top of the cradle to ensure sealing of the connections and avoid any communication between the external fluid (water) used to apply the desired confining pressure and the internal dead volume in the rock core during the course of the fracturing experiment. The rock core in the cradle was then connected to the head of a high pressure vessel (High Pressure Equipment Company, Erie, PA), and the cradle was introduced to the pressure vessel. A 3-way valve was used to deliver polymer solution and $\mathrm{CO}_{2}$. The temperature of the reactor was controlled with heating tape, a

thermocouple, and a temperature controller. After the target temperature was reached, water was injected into the pressure vessel using a syringe pump to increase confining pressure. The confining pressure was first increased to either 68 atm, immediately followed by introduction of $200 \mu \mathrm{L}$ of $1 \mathrm{wt} \%$ PAA solution and $68 \mathrm{~atm}$ of $\mathrm{CO}_{2}$ inside the core sample via the three-way valve. Then, the confining pressure and rock core pressure were increased in 3.4 atm (50 psi) 
132 intervals until the target pressure was achieved. Subsequently, the rock core internal pressure 133 was gradually increased in intervals of 1 atm with the fracturing fluid while maintaining the 134 confining pressure constant, until an increase in the confining pressure was observed. This 135 pressure equilibration indicates communication between the internal and external fluids as a 136 result of fracture formation/propagation. The pressure difference between the applied fracturing

137 fluid pressure required for rock core fracturing and the confining pressure is defined as "effective 138 pressure" or "effective stress." After pressure equalization was observed, the system was cooled 139 to room temperature and the pressure was released before the pressure vessel was opened and the 140 rock core retrieved. For comparison, control fracturing experiments using $\mathrm{DIW} / \mathrm{CO}_{2}$ were also 141 performed at identical experimental conditions for comparison purposes. The rock cores

142 retrieved from the high pressure vessel after fracturing experiments were subjected to a series of 143 tests to examine the formation and distribution of fractures as described below. Hydraulic 144 fracturing experiments were performed at $150{ }^{\circ} \mathrm{C}$ and $250 \mathrm{~atm}$ as well as at $300{ }^{\circ} \mathrm{C}$ and 330 atm 145 with $1 \mathrm{wt} \%$ PAA solution to evaluate the fracturing fluid technology at low and high EGS 146 temperature and pressure limits. In addition, we also conducted the fracking experiments with 147 PAA solution prepared in $\mathrm{pH} 7$ and 10 buffer solutions to test the effect of reservoir fluid $\mathrm{pH}$ on 148 the effectiveness of the fracturing fluid to enhance permeability. Experiments at $\mathrm{pH}=7$ and $149 \mathrm{pH}=10$ were conducted at $300^{\circ} \mathrm{C}$ and 333 atm with rock from the Coso site.

\subsection{Post experiment fracture connectivity measurements}

151 Gas leaking test (gas bubbling experiment) was performed for each core after fracturing 152 experiment to verify the presence of fractures connected to the external surface of the sample 153 (see Fig. S3 for an example of this test). This experiment was conducted by injecting $\mathrm{N}_{2}$ gas at 
154 6-10 atm into the center hole of the rock core. The core was placed inside water, so the fracture 155 opening to the external surface of the rock cores can be identified by the appearance of gas 156 bubbles. The pressure was maintained at low levels (6-10 atm) to minimize the potential creation 157 of new fractures during the gas leaking tests.

\subsection{Post experiment permeability measurement}

Pre-experiment rock intrinsic permeability values were below the lower limit of measurement. However, the intrinsic permeability of the fractures formed after fracturing experiments were calculated from measurements of tracer travel time through fractured core within the high pressure vessel using $1 \mathrm{M}$ copper acetate solution. The blue colored solution was injected into the fractured rock cores using a water-filled syringe pump to allow the application of a constant pressure gradient of 6-8 atm. The time when the blue colored solution was observed at the region where gas leakage occurred was used to calculate the seepage velocity, which in turn was used to calculate the permeability using Darcy's law (Equation 3). The time intervals recorded to estimate the permeability on post-fractured rock samples ranged from 1.5 to $240 \mathrm{sec}$ with an error of $0.3 \mathrm{sec}$ based on multiplying by a factor of 2 the minimum time required to start or stop the timer. Since we do not know explicitly the exact fracture pathway in the rock core, we assumed that the pathways of all the fractures were straight lines perpendicular to the central hole and extend directly from the central hole to the external surface (i.e., $0.635 \mathrm{~cm})$. It is noteworthy that more than likely this assumption underestimates the actual fracture pathway.

Therefore, the measured permeability represents the lower limit of the intrinsic permeability. The permeabilities obtained by this method are referred here in as experimental permeabilities to differentiate them from the permeability values obtained by computational fluid dynamics (CFD) 

177 permeabilities.

modeling in two representative rock cores which will be referred in the text as model-estimated

\subsection{X-ray microtomography (XMT) analysis}

XMT scanning was performed at $110 \mathrm{keV}$ and $190 \mu \mathrm{A}$ for optimum image quality and contrast. The samples were rotated continuously during the scans with momentary stops to collect each projection (shuttling mode) and minimize ring artifacts. A total of 3142 projections were collected over 360 degrees with 0.5 second exposure time and 4 frames per projection. Image voxel size varied from $25-30 \mu \mathrm{m}$ depending on specimen dimensions. The images were reconstructed to obtain three-dimensional datasets using CT Pro 3D (Metris XT 2.2, Nikon Metrology, UK). For rock cores after fracturing experiment, pressurized scans were conducted using a cell containing the sample (Fig. S3) connected to a nitrogen tank regulated to 8 atm (similar to pressure gradient of permeability measurements). The cell was made of polyether ether ketone (PEEK) to minimize the adsorption of $\mathrm{x}$-ray.

\subsection{Computational Fluid Dynamics (CFD) modeling of hydraulic fractures}

CFD simulations were performed in two representative post-fractured rock samples (Coso 110 and Newberry-4) to visualize flow characteristics in the hydraulic fractures and to compute bulk permeability, from herein model-estimated permeability. Detailed description of XMT image segmentation, mesh generation and fluid flow simulations can be found elsewhere. ${ }^{12,13}$ Briefly, the XMT images were pre-processed in ImageJ to remove any low frequency noise. Intensity thresholds followed by manual validation were performed to identify the fracture boundaries. An isosurface from the segmented data was extracted using a variant of marching 
197 cube algorithm ${ }^{14}$ and smoothed using volume conserving smoothing. ${ }^{15}$ The isosurface was 198 imported in Magics (Materialise, Plymouth, MI, USA) to clean up any intersecting and 199 overlapping triangles and also to create a flat inlet surface for boundary condition specification.

200 The outlet boundary in this case was outside surface of the rock core. The final surface from 201 Magics was imported, remeshed and volume meshes were generated using the standard 202 tetrahedral meshing utility in STARCCM+ (CD-Adapco). The final volume mesh for the 203 samples Coso -1-10 and Newberry 4 consisted of 516112 and 2762135 vertexes, 4678568 and 20426021566 faces, and 2197594 and 12342917 tetrahedral elements, respectively. A mesh 205 independence study was performed using hybrid prism/tetrahedral meshes generated in 206 STARCCM+. The tightly packed boundary layer consisted of prismatic elements to accurately 207 capture boundary layer formation at the fracture walls. Tetrahedral mesh elements constituted the 208 core of the volume mesh. The simulation results from the tetrahedral meshes were considered 209 independent of mesh density since the difference in flow field between the tetrahedral mesh and 210 the hybrid prism/tetrahedral mesh were less than $6 \%$.

212 simulation. The flow predictions were based upon the laminar, 3-D, incompressible Navier213 Stokes equations for fluid mass and momentum:

$$
\frac{\partial u}{\partial t}+u \cdot \nabla u=-\frac{\nabla p}{\rho}+v \nabla^{2} u
$$


216 where $\rho$ is the density, $v$ is the kinematic viscosity, $u$ is the fluid velocity vector, and $p$ is the

217 pressure.

For Coso-1-10, water at $300^{\circ} \mathrm{C}$ temperature and 100 atm pressure was considered to be

219 the working fluid, with a density of $712.04 \mathrm{~kg} / \mathrm{m}^{3}$ and a kinematic viscosity of $1.2078 \times 10^{-7} \mathrm{~m}^{2} / \mathrm{s}$.

220 For Newberry 4 , water at $150^{\circ} \mathrm{C}$ temperature and $100 \mathrm{~atm}$ pressure was considered to be the

221 working fluid, with a density of $918 \mathrm{~kg} / \mathrm{m}^{3}$ and a kinematic viscosity of $2.069 \times 10^{-7} \mathrm{~m}^{2} / \mathrm{s}$. The

222 proximal end of the drill hole was assumed the inlet and outside surface of the rock core was

223 assumed to be the outlet. Both models were driven by a predetermined flow rate specified at the

224 inlet and a zero pressure boundary condition at the outlet. A no-slip wall condition was applied

225 to the fracture boundaries, which were assumed to be rigid and impermeable.

226 Using the model's specified pressure gradient, the spatial distribution of velocity was 227 predicted and intrinsic permeability was also calculated using the Darcy's law as given below:

228

$$
\mathrm{q}=-\mathrm{k} / \mu \times \nabla \mathrm{P}
$$

230 where $\mathrm{q}$ is the flux $(\mathrm{m} / \mathrm{s}), \mu$ is the dynamic viscosity of fluid, and $\nabla \mathrm{P}$ is the pressure gradient 231 vector $(\mathrm{Pa} / \mathrm{m})$.

\section{3. Results and Discussion}

\section{$233 \quad 3.1$ Hydraulic fracturing experiments}

234 It is well known that temperature and pressure in different geothermal sites varies with depth 235 and the relationship between temperature and depth is significantly different for different US 


\begin{tabular}{|c|c|c|c|c|c|c|c|}
\hline $\begin{array}{l}\text { Exp. } \\
\text { No. }\end{array}$ & Core name & $\begin{array}{c}\text { Temp. } \\
\left({ }^{\circ} \mathrm{C}\right)\end{array}$ & $\begin{array}{l}\text { Pressure } \\
\text { (atm) }\end{array}$ & Fracking fluid & $\begin{array}{c}\text { Effective } \\
\text { pressure of } \\
\text { rock fracking. } \\
(\text { atm) }\end{array}$ & $\begin{array}{l}\text { Permeability } \\
\text { after fracking } \\
\text { exp. }(\mathrm{mD})\end{array}$ & $\begin{array}{c}\text { Gas } \\
\text { leaking test }\end{array}$ \\
\hline
\end{tabular}

236 geothermal sites as reported by the US-DOE Geothermal Technology Office (DOE-GTO). To

237 evaluate fracturing applicability across this variability, a total of 13 rock cores from two

238 geothermal sites were subjected to hydraulic fracturing under different experimental conditions

239 spanning the known range of EGS site temperatures, pressures, and reservoir $\mathrm{pH}$. The

240 permeability values for each sample were determined experimentally with two exceptions

241 (samples Coso 1-10 and Newberry-4) were both, experimental and model-estimated permeability

242 were determined. The experimental conditions and the results, including experimental

243 permeabilities, are summarized in Table 1. Model-estimated permeabilities for Coso 1-10 and

$244 \quad$ Newberry-4 are discussed in section 3.2.

245 Table 1. Conditions of hydraulic fracturing experiments 


\begin{tabular}{|c|c|c|c|c|c|c|c|}
\hline 1 & Coso-1-10 & 300 & 333 & PAA- $\mathrm{CO}_{2}$ & 17 & 8.8 & Yes \\
\hline 2 & Coso-1-19 & 300 & 333 & $\mathrm{DIW} / \mathrm{CO}_{2}$ & $>170^{a}$ & $<0.001^{b}$ & $\mathrm{No}^{c}$ \\
\hline 3 & Newberry-01 & 300 & 333 & $\mathrm{PAA}-\mathrm{CO}_{2}$ & 114 & 0.031 & Yes \\
\hline 4 & Newberry-03 & 300 & 333 & $\mathrm{PAA}-\mathrm{CO}_{2}$ & 82 & 0.032 & Yes \\
\hline 5 & Newberry-02 & 300 & 333 & DIW/CO ${ }_{2}$ & $>170^{a}$ & $<0.001$ & $\mathrm{No}^{c}$ \\
\hline 6 & Coso-1-9 & 150 & 250 & $\mathrm{PAA}-\mathrm{CO}_{2}$ & 34 & 8.8 & Yes \\
\hline 7 & Coso-1-18 & 150 & 250 & $\mathrm{DIW} / \mathrm{CO}_{2}$ & 49 & $<0.001$ & Yes \\
\hline 8 & Newberry-04 & 150 & 250 & $\mathrm{PAA}-\mathrm{CO}_{2}$ & 133 & 5.3 & Yes \\
\hline 9 & Newberry-08 & 150 & 250 & $\mathrm{DIW} / \mathrm{CO}_{2}$ & $>170^{a}$ & $<0.001$ & No \\
\hline 10 & Coso-1-14 & 300 & 333 & PAA (pH7)- $-\mathrm{CO}_{2}$ & 27 & 2.0 & Yes \\
\hline 11 & Coso-1-16 & 300 & 333 & pH 7 buffer- $-\mathrm{CO}_{2}$ & 45 & 0.60 & Yes \\
\hline 12 & Coso-1-15 & 300 & 333 & $\mathrm{PAA}(\mathrm{pH} 10)-\mathrm{CO}_{2}$ & 24 & 0.35 & Yes \\
\hline 13 & Coso-1-17 & 300 & 333 & pH10 buffer- $\mathrm{CO}_{2}$ & 41 & 0.032 & Yes \\
\hline
\end{tabular}

a: No communication observed even at maximum pressure allowed by the pump. Also, gas leaking test and XMT analysis did not indicate any fractures on this rock core; $b$ : no liquid was observed on the external surface even after applying $10 \mathrm{~atm}$ pressure to the center hole for $5 \mathrm{~min}$, suggesting the permeability is lower than $0.001 \mathrm{mD}$. c: no gas flow observed

\subsubsection{Effects of temperature and pressure}

\subsubsection{Fracturing experiments conducted at $300^{\circ} \mathrm{C}$ and $333 \mathrm{~atm}$ conditions}

Experiments \#1 through \#5 were conducted with rock cores from Coso and Newberry geothermal sites at $300^{\circ} \mathrm{C}$, which falls in the upper range of US geothermal sites and correspond to depth of $1585 \mathrm{~m}$ (5200 ft) below surface for Coso geothermal site ${ }^{2,3}$. Rock core Coso 1-10 (Experiment \#1) was fractured applying an effective pressure of only 17 atm with $\mathrm{PAA}-\mathrm{CO}_{2}$ fracturing fluid system, whereas Coso 1-19 (Experiment \#2, a control experiment with DIW-CO was not fractured even when the internal pressure was 170 atm higher than the confining pressure (note that at this effective pressure, the pressure of $\mathrm{CO}_{2}$ was actually near the upper limit of the ISCO pump). Gas leaking test for Coso 1-10 showed that $\mathrm{N}_{2}$ bubbles appeared immediately and profusely and occurred within the top $2.54 \mathrm{~cm}$ of the rock core, consistent with 
262

263

264

265

266

267

268

269

270

271

272

273

274

275

276

277

278

279

280

281

282

283

284

285

the location of the center hole $(2.54 \mathrm{~cm}$ depth) where the hydraulic fracturing fluid was injected (Fig. S4). XMT analysis showed no presence of preexisting fractures on Coso 1-10 before the fracturing experiment, while after fracturing experiment fractures can be clearly seen and extend approximately $2 \mathrm{~cm}$ longitudinally (Fig. 2).

Fig. 2. XMT images of Coso 1-10 before (left) and after (right) hydraulic fracturing experiment. Control experiment (\#2, coso-1-19) did not show the presence of fractures even at differential pressures as high as $170 \mathrm{~atm}$. The fractures extended $\sim 0.5 \mathrm{~mm}$ above and $\sim 17 \mathrm{~mm}$ below this transversal section.

The experimental permeability of Coso-1-10 after fracturing was determined to be approximately $8.8 \mathrm{mD}$, which is comparable to the typical permeability of sandstone reservoir rocks ${ }^{16}$. It is noteworthy that, as we discussed in Section 2.4 , the actual intrinsic permeability could be higher than the experimental permeability reported in Table 1 due to the assumptions employed for its calculation. When we determined the experimental permeability for Coso 1-19, no liquid was observed on the external surface of Coso 1-19 after applying 10 atm pressure on the center hole for $5 \mathrm{~min}$. Based on this result, we estimate that the permeability of Coso-1-19 after fracturing experiment is less than $0.001 \mathrm{mD}$. Thus, the permeability of Coso rock core fractured with a conventional fracturing fluid (Coso 1-19) is at least three orders of magnitude lower than the permeability of a Coso rock core fractured with $\mathrm{PAA}-\mathrm{CO}_{2}$ fracturing fluid (Coso 1-10). Previous studies have shown that Coso geothermal field rock consist mainly of diorite which is highly impermeable rock with compressive strengths in the range of 1500-2000 atm. ${ }^{17}$ ${ }^{18}$ Coso 1-10 was fractured with an applied effective stress of 17 atm when employing $\mathrm{PAA}-\mathrm{CO}_{2}$ fracturing fluid as compared to more than 170 atm for an identical rock core (Coso 1-19, control experiment), suggesting that the novel PAA- $\mathrm{CO}_{2}$ fracturing fluid can create/propagate fractures 
286 in highly impermeable crystalline rock. Additional fracturing experiments were conducted with

287 rock cores collected from another geothermal site, the Newberry crater site, under identical

288 conditions $\left(300^{\circ} \mathrm{C}\right.$ and 333 atm). Newberry geothermal reservoir cores consist of highly

289 impermeable (order of $10^{-6} \mathrm{mD}$ ) siliceous volcanic rocks obtained at $700+\mathrm{m} \mathrm{depth} .{ }^{19}$ For the

290 control experiment conducted with DIW-CO $\mathrm{CO}_{2}$ (Table 1), the rock core (Newberry-02) was not

291 fractured even when internal pressure was 170 atm higher than the confining pressure. Similarly

292 to the control experiment for Coso field rock core (Coso 1-19), no $\mathrm{N}_{2}$ leaking was observed for

293 Newberry-02 after the fracturing experiment. When employing $\mathrm{PAA}-\mathrm{CO}_{2}$ as a fracturing fluid,

294 however, similar Newberry rock cores [Newberry-01(experiment \#3) and Newberry-03

295 (experiment \#4)] were successfully fractured at significantly lower effective pressures (see Table

296 1). $\mathrm{N}_{2}$ leaking test revealed the presence of connecting fractures and the experimental

297 permeability of the two fractured cores was similar (0.031 and $0.032 \mathrm{mD}$, respectively) (Table 1),

298 showing an increase in permeability with respect to the original unaltered Newberry rock

299 samples of over four orders of magnitude $\left(0.032 \mathrm{mD} \text { vs. } 10^{-6} \mathrm{mD}\right)^{19}$. Although both gas leaking

300 tests and experimental permeability values suggest that fractures were successfully created for

301 Newberry 01 and 03, results from XMT analysis indicate that the fractures obtained consist of

302 micro-fractures with apertures equal or below the resolution limit of the instrument (voxel size=

$303 \sim 25-30 \mu \mathrm{m}$, data not shown).

\subsubsection{Fracturing experiments conducted at $150{ }^{\circ} \mathrm{C}$ and $250 \mathrm{~atm}$ conditions}

A second set of experiments was performed at a lower limit of P/T conditions in US EGS

306 reservoirs as reported by the DOE-GTO. These fracturing experiments were carried out at 250

307 atm and at a temperature of $150{ }^{\circ} \mathrm{C}$, corresponding to some locations drilled at the Desert Peak 
and Newberry EGS sites. ${ }^{2,3}$ Table 1 (experiment \#6 through \#9) shows that the effective stress

309 required to create/propagate fracture network is significantly lower when employing $\mathrm{PAA}-\mathrm{CO}_{2}$

310 rheoreversible fracturing fluids to fracture both Coso and Newberry rock cores, and that the

311 experimental permeability of the generated fracture networks is considerably and consistently

312 higher than those obtained using DIW/CO 2 (control experiments). For example, using $\mathrm{PAA}-\mathrm{CO}_{2}$

313 fracturing fluid in a EGS Coso rock core (Coso 1-9) the sample was fractured with an effective

314 stress of 34 atm while a nearly $50 \%$ increase in effective stress was required to fracture an

315 identical sample (Coso 1-18) when using a conventional fracturing fluid (control experiment). In

316 addition, the experimental permeability value for the Coso sample fractured with the $\mathrm{PAA}-\mathrm{CO}_{2}$

317 fluid system was in the order of several $\mathrm{mD}$, which is nearly four orders of magnitudes higher

318 than the experimental permeability obtained in a Coso rock sample fractured with the

319 conventional fracturing fluid (Coso 1-18). Fig. 3 shows the XMT micrographs obtained from

320 Coso 1-9 showing fracture networks generated by the novel $\mathrm{PAA}-\mathrm{CO}_{2}$ fracturing fluid. On the

321 other hand, no evidence of fractures (to the resolution limit of the instrument) was observed on

322 XMT images of Coso 1-18 sample which was subjected to $\mathrm{DIW} / \mathrm{CO}_{2}$ hydraulic fracturing fluid

323 (data not shown). Fracture micrographs of a Newberry sample (Newberry-04) fractured with

324 PAA- $\mathrm{CO}_{2}$ fracturing fluid at $150{ }^{\circ} \mathrm{C}$ and 250 atm are shown in Fig. 4 manifesting the presence of

325 fractures that communicate the center hole of the rock sample with the external surface.

326 Newberry samples subjected to $\mathrm{DIW} / \mathrm{CO}_{2}$ fracturing fluids (control experiment) show no

327 observable fracture networks. 
Fig. 3. XMT images of rock cores Coso 1-9 before (left) and after (right) hydraulic fracturing experiment. Control experiment (\#8, Coso 1-18) did not show the presence of fractures. The fractures extend $\sim 10 \mathrm{~mm}$ above and $\sim 5 \mathrm{~mm}$ below this transversal section.

Fig. 4. XMT images of Newberry-04 rock core fractured with PAA-CO2 fracturing fluid. The Figure shows sample micrographs before (left) and after (right) hydraulic fracturing experiment. The fractures extend $\sim 0.4 \mathrm{~mm}$ above and $\sim 1.5 \mathrm{~mm}$ below this transversal section. Control experiment (Newberry-08) did not show the presence of fractures.

The results from these experiments suggest that, 1) similarly to previous high temperature experiments, under low temperature and pressure conditions, $\mathrm{PAA}-\mathrm{CO}_{2}$ fracturing fluids can generate highly permeable fracture networks in highly impermeable crystalline rock cores from both Coso and Newberry geothermal sites at significantly lower effective stress than the cores subjected to hydraulic fracturing with $\mathrm{DIW}-\mathrm{CO}_{2}$ (control experiments); 2) the permeability of the fracture networks generated with $\mathrm{PAA}-\mathrm{CO}_{2}$ fracturing fluid is several orders of magnitude higher than the permeability of identical rock samples subjected to a conventional fracturing fluid independent of the experimental confining pressure and temperature. The versatility of these rheoreversible fracturing fluids at both low and high EGS temperatures is then demonstrated at the laboratory scale. It is important to notice that at lower confining temperature and pressure, the effective pressures needed to fracture these rock cores is higher than that required at higher confining temperature and pressure. For example, while only 17 atm of effective stress is needed to fracture Coso-1-10 at $300{ }^{\circ} \mathrm{C}-333$ atm with $\mathrm{PAA}-\mathrm{CO}_{2}$ fluid systems, more than twice as high (effective) pressure (34 atm) was needed to create/propagate fracture networks when identical Coso rock cores are subjected to confining P/T of $150{ }^{\circ} \mathrm{C}$ and 250 atm. The higher effective pressures required for $\mathrm{PAA}-\mathrm{CO}_{2}$ fluid system to generate similar fracture 
networks at lower T/P conditions as compared to experiments performed at confining $\mathrm{P} / \mathrm{T}$ of 333

354 bar and $300 \mathrm{C}$ is related to the temperature-dependent volume expansion of PAA under different $355 \mathrm{CO}_{2}$ pressures. In our previous study we have demonstrated that at low temperatures $\left(127^{\circ} \mathrm{C}\right)$, 356 only limited volume expansion (less than 40\%) was observed, while at higher temperatures (196$357402{ }^{\circ} \mathrm{C}$ ) volume expansions of up to 2.5 times the original volume was recorded with higher 358 volume expansions at higher temperatures. ${ }^{11}$. Nevertheless, the largely decreased effective stress 359 required to create/propagate fracture networks within highly impermeable rock cores at very different $\mathrm{P} / \mathrm{T}$ conditions suggests the potential of $\mathrm{PAA}-\mathrm{CO}_{2}$ fracturing fluid to reduce energy and

361 cost during reservoir stimulation. Furthermore, the much higher (orders of magnitude)

362 experimental permeabilities measured upon fracturing with this novel fluid as compared to 363 conventional fluids position them as important fracturing fluid candidates to enhance 364 permeability in EGS. For this initial set of experiments where the priority was to demonstrate the 365 efficiency of the PAA- $\mathrm{CO}_{2}$ fluid in fracturing rocks commonly encountered in geothermal 366 environment, information on the mechanical properties of the rock samples were not available. 367 It is planned in a near future to conduct two new series of experiments: (1) on homogeneous 368 well- characterized natural or synthetic materials with mechanical properties close to crystalline 369 rocks to determine the intimate fracturing mechanism and exact role of the fluid and build a 370 predictive modelling; (2) on real rock samples coming from geothermal fields with known 371 mechanical properties and heterogeneities to validate the proposed model.

\section{$372 \quad$ 3.1.2 Effects of EGS reservoir $\mathbf{p H}$}

373 The formation water chemistry and $\mathrm{pH}$ of brine solutions varies from one geothermal site to 374 another one with the majority of geothermal sites in U.S. reporting $\mathrm{pH}$ values in the range of 6- 
37510 (a few sites report pHs as low as 4$)^{20}$. Then, to evaluate if this newly developed fracturing

376 fluids can perform well at different $\mathrm{pH}$ conditions, four experiments (experiments \# 10 through-

377 13) were conducted with rock cores from Coso geothermal field at $300{ }^{\circ} \mathrm{C}$ and 333 atm and at

378 solution $\mathrm{pH} 7$ and 10. PAA/CO 2 -based and control fracturing fluid experiments (Coso 1-14 and

379 Coso 1-16) were conducted employing a $\mathrm{pH}=7$ buffer (with and without PAA, respectively).

380

381

382

383

384

385

386

387

388

389

390

391

392

393

394

395

396

397

398

Fig. 5. Representative XMT images of Coso 1-14 (a, b) and Coso 1-16 (c, d) rock cores before and after hydraulic fracturing experiment. The arrows point to the fractures. Note the much larger aperture of the fractures created on Coso 1-14.

The results shows that Coso 1-14 was fractured at an effective stress of 27 atm (Table 1), while the effective stress required to fracture an identical rock core using the conventional fracturing fluid (control experiment, Coso-1-16) was nearly $70 \%$ higher. Similarly, the experimental permeability values of Coso-1-14 fractured with $\mathrm{PAA}^{-\mathrm{CO}_{2}}$ fluid system was 2.0 $\mathrm{mD}$, which is nearly four times higher than the experimental permeability obtained when fracturing with a conventional fluid (control experiment, Coso 1-16). XMT analyses also provide evidence that the fractures on Coso 1-14 were larger than Coso 1-16 demonstrating once again the potential of $\mathrm{PAA}-\mathrm{CO}_{2}$ fracturing fluids for creation/propagation of fracture networks in highly impermeable crystalline rock (Fig. 5). Fig. 5 shows that the fractures in rock sample Coso 1-14 were located about $0.5 \mathrm{~mm}$ from the top and extended longitudinally $10 \mathrm{~mm}$ further down.

Fig. 6. XMT images of rock cores Coso-1-15 (fractured with PAA-CO2, top) and Coso-1-17 (fractured with DIW-CO2, bottom) before (left) and after (right) hydraulic fracturing experiment. Note the significant larger aperture on Coso-1-15. The fractures on Coso-1015 extended $\sim 3 \mathrm{~mm}$ above and $\sim 6 \mathrm{~mm}$ below this this transversal section shown in the figure. 
Similar experiments were performed in $\mathrm{pH}=10$ buffer solutions and similar results were 400 obtained (see Table 1, experiments \#12 and \#13). Fig. 6 shows the fractures created/propagated

401 from the center hole to the rock external surface in both samples. Effective stress as low as 24

402 atm was required to create/propagate fracture networks in Coso 1-15, as compared to a $70 \%$

403 higher effective stress required to create fracture networks in Coso 1-17 using DIW-CO

404 fracturing fluid system. Furthermore, the experimental permeability resulting from fracturing

405 Coso 1-15 with PAA- $\mathrm{CO}_{2}$ fluid was an order of magnitude higher than the experimental

406 permeability of the fracture network created when employing DIW- $\mathrm{CO}_{2}$ control fracturing fluid.

407 The results demonstrate that the novel fracturing fluid $\mathrm{PAA}-\mathrm{CO}_{2}$ can reproducibly generate

408 fracture networks and significantly enhance permeability in highly impermeable rock cores at

409 different reservoir $\mathrm{pHs}$ further validating the versatility of $\mathrm{PAA}-\mathrm{CO}_{2}$ fluid systems for potential

410 EGS reservoir stimulation.

\subsection{CFD modeling and fracture network description}

413 CFD modeling was conducted for two rock cores, Coso-1-10 and Newberry-04, which

414 represent the two geothermal field sample rock types and the lower and upper EGS pressure and

415 temperature limits. The simulations were used to characterize the spatial distribution and fluid

416 flow characteristics of the post-experiment fractures and permeability distribution within each of

417 the fractures created by the novel PAA fracturing method in two illustrative example

418 experiments. 
Figure 7 shows velocity vectors for the Coso 1-10. The fractures produced during the

421 fracture experiment were annotated as fracture 1 and 2 as shown in the Fig. 7. Since the volume

422 of the fracture 1 is greater than fracture 2 , the volumetric fluid flow in fracture 1 is greater. The

423 higher volumetric flow through fracture 1 can also be attributed to its better connectivity with the

424 central drill hole. The normalized permeability of fracture 1 and 2 computed using Darcy's law

425 were $2.19 \times 10^{-13} \mathrm{~m}^{2}(222 \mathrm{mD})$ and $6.24 \times 10^{-14} \mathrm{~m}^{2}(63.2 \mathrm{mD})$, respectively, and the bulk core

426 model-estimated permeability was $2.48 \times 10^{-13} \mathrm{~m}^{2}(251 \mathrm{mD})$.

427 Fig. 7. CFD model of Coso 1-10 showing: left: isosurface of fractures 1 and 2 for Coso 1-10 with 428 XMT data (left). The inlet was extruded during volume meshing to improve solution 429 convergence. Middle: CFD model of Coso 1-10 showing velocity vectors colored by absolute 430 velocity. The flow rate and velocity of the flow in fracture 1 is higher than fracture 2 due to 431 smaller cross-sectional area but higher fracture volume. Right: contours of static pressure 432 showing gradient along the fracture wall.

\subsubsection{Newberry-04}

Similar to Coso 1-10, the fracture experiment resulted in two fractures named 1 and 2,

436 (see Fig. 8) but these fractures merge together in the distal portion of the sample (lower end of

437 the drill hole). From the plot of velocity vector colored by absolute velocity, we can notice fluid

438 velocity in fractures 1 and 2 to be similar in magnitude. The volumetric flows in both fractures

439 are also similar. This could be attributed to the fact that both fractures have similar aperture sizes

440 and also fracture volumes. In the distal portion of the sample, a slightly higher fluid velocity

441 region can be noticed due to narrowing of the fracture aperture. Since fracture permeability

442 depends on fluid flow characteristics, the similarity between fractures 1 and 2 results in similar 
permeabilities. The (rock) volume-normalized permeability of fracture 1 and 2 were $1.83 \times 10^{-13}$ $\mathrm{m}^{2}(185 \mathrm{mD})$ and $1.94 \times 10^{-13} \mathrm{~m}^{2}(196 \mathrm{mD})$, respectively, and the bulk core model-estimated permeability was $3.78 \times 10^{-13} \mathrm{~m}^{2}(383 \mathrm{mD})$. The similarity in flow characteristics and permeability between fractures 1 and 2 suggest isotropic behavior of the fracture network.

Fig. 8. CFD model of Newberry-04 showing: Left: a slice of XMT data with isosurface generated using segmented data for Newberry 4 sample. The interface between the rock and the rock core cradle was assumed as the outlet for the CFD model. Middle: CFD model of Newberry-04 showing velocity vectors colored by absolute velocity. Volumetric flow and fluid velocity in both fracture 1 and 2 are similar since the volumes and apertures of fractures 1 and 2 are comparable. Right: contours of static pressure.

It is important to mention the apparent discrepancy between the model-estimated fractures network permeabilities and the experimental permeability values measured. These differences in permeability could be attributed to the following reasons. 1) Fluid flow was modeled at steady state, hence, energy loss due to acceleration of fluid was not accounted. On the other hand, the experimental setup accounted for inertial losses due to fluid acceleration while increasing the pressure gradient; 2) using the computational model, individual permeabilities were computed for the two fractures for both Newberry 4 and Coso 1-10 where the experimental procedure measured only the permeability of one fracture or the fracture where the colored solution was first seen; 3) the length of the fracture used for the experimental determination was assumed to be the diameter of the sample less the central void which is a simplification; 4) time for the color solution to traverse the fracture was timed using a chronometer, which was prone to human errors.

\section{Conclusions}


hydrocarbon extraction rates are only expected to increase despite concerns over $\mathrm{CO}_{2}$ emissions

469 and potential climate change impacts. Geothermal energy represents one of the most promising

470 renewable sources of energy within the US and worldwide. Current locations viable for

471 geothermal production are limited by formation permeability, and enhancing formation

472 permeability, as in Enhanced Geothermal Systems (EGS), is required to expand geothermal

473 energy production. The primary limitation that makes commercial EGS infeasible is our current

474 inability to cost-effectively create high-permeability reservoirs from impermeable, igneous rock

475 within the 1-4 km depth range. Fracturing for oil and gas is now standard practice, but the

476 applicability of the conventional fracturing methods and chemicals at elevated EGS temperatures

477 and pressures is uncertain. In addition, there is a widespread concern about the synthetic and

478 highly-proprietary chemicals employed in conventional fracturing and the resulting potential

479 contamination of shallow drinking water aquifers. This work evaluates at the laboratory scale the

480 EGS applicability of a novel, environmentally-friendly and potentially recyclable hydraulic

481 fracturing fluid that undergoes a controlled and large-volume expansion with a simultaneous

482 increase in viscosity triggered by $\mathrm{CO}_{2}$ at temperatures relevant for reservoir stimulation in EGS.

483 The results illustrate the versatility of this novel fracturing fluid for EGS applications. The

484 phase-switchable fluid fractures impermeable igneous rocks at lower effective stresses, and 485 increases permeability to a significantly (several orders of magnitude) larger level, compared to 486 conventional hydraulic fracturing methods. This is confirmed for two rock types from

487 geothermal fields, over the entire range of EGS pressures and temperatures, and over a wide 488 range of formation $\mathrm{pH}$ values, which confirms the feasibility of this novel method for formation 
stimulation and potential development of EGS at various locations world-wide. With softer rocks

490 and lower pressure formations, this novel fracturing fluid would be viable for enhancing

491 hydrocarbon production, as well. The efficiency and effectiveness of the permeability

492 enhancement combined with the potential extractability of the switchable fluid make this novel

493 fracturing method more cost-effective and environmentally cleaner than current approaches.

\section{Acknowledgements}

495 Funding for this research was provided by the Geothermal Technology Office of the U.S.

496 Department of Energy. XMT analysis was performed in EMSL (Environmental Molecular

497 Sciences Laboratory; EMSL proposal \# 47743), a DOE national scientific user facility at Pacific

498 Northwest National Laboratory (PNNL). Pacific Northwest National Laboratory is operated by

499 Battelle for the U.S. Department of Energy under contract DE-AC06-76RLO 1830.

\section{Supporting Information}

501 Schematic diagram and photos of rock core cradle setup, photos of gas leakage test, and XMT

502 images of rock cores before and after hydraulic fracturing experiments are included in the

503 supporting information.

\section{References}

505

506

507

508

509

510

511

512

513

514
1. D. D. Blackwell, P. T. Negraru and M. C. Richards, Natural Resources Research, 2006, 15, 283-303.

2. W. A. Duffield and J. H. Sass, U.S. Geol. Surv. Circ., 1249, 2003.

3. K. Pruess, Geothermics, 2006, 35, 351-367.

4. D. M. Kargbo, R. G. Wilhelm and D. J. Campbell, Environmental Science \& Technology, 2010, 44, 5679-5684.

5. R. A. Kerr, Science, 2010, 328, 1624-1626.

6. J. W. Tester, Massachusetts Institute of Technology, Boston, 2006.

7. F. Garcia-Ochoa, V. E. Santos, J. A. Casas and E. Gomez, Biotechnology Advances, 2000, 18, 549579. 
$515 \quad 8 . \quad$ B. N. Jang, M. Costache and C. A. Wilkie, Polymer, 2005, 46, 10678-10687.

516 9. M. Wang, J. M. Smith and B. J. McCoy, AICHE Journal, 1995, 41, 1521-1533.

517 10. I. C. Scotchman, in Issues in Environmental Science and Technology, ed. R. E. H. Hester, R. M., 518 RSC, 2014.

519 11. H. B. Jung, S. Kabilan, D. J. Heldebrant, D. Hoyt, L. Zhong, T. Varga, S. Stephens, L. Adams, K. C. Carroll, A. Bonneville, A. Kuprat and C. A. Fernandez, Under review, 2014.

12. J. P. Carson, D. R. Einstein, K. R. Minard, M. V. Fanucchi, C. D. Wallis and R. A. Corley, Computerized Medical Imaging and Graphics, 2010, 34, 572-578.

13. J. P. Carson, A. P. Kuprat, X. Jiao, V. Dyedov, F. Del Pin, J. M. Guccione, M. B. Ratcliffe and D. R. Einstein, Biomechanics and modeling in mechanobiology, 2010, 9, 187-201.

14. W. E. Lorensen and H. E. Cline, ACM SIGGRAPH Computer Graphics, 1987, 21, 163-169.

15. A. Kuprat, A. Khamayseh, D. George and L. Larkey, Journal of Computational Physics, 2001, 172, 99-118.

16. H. Pape, C. Clauser and J. Iffland, Geophysics, 1999, 64, 1447-1460.

17. D. A. Berkman, Field geologist's manual The Australasian Institute of Mining and Metallurgy, Australia, 2001.

18. N. C. Davatzes and S. H. Hickman, Stress and faulting in the Coso Geothermal Field: update and recent results from the East Flank and Coso Wash, 31st workshop on Geothermal Reservoir Engineering, Standford University, Stanford, CA, Standford University, Stanford, CA, Jan 30-Feb 1, SGP-TR-179, 2006.

19. K. E. Bargar and T. E. C. Keith, U.S. Geological Survey Professional Paper 1578, available online: http://pubs.usgs.gov/pp/pp1578/ (accessed Sep-2014), 2000.

20. C. E. Clark, C. B. Harto, J. L. Sullivan and M. Q. Wang, Prepared for the US DOE EERE Geothermal Technologies Program, under contract DE-AC02-06CH11357. Argonne National Laboratory, ANL/EVS/R-10/5, 2010. 
541 TOC/Abstract Art

542

543 


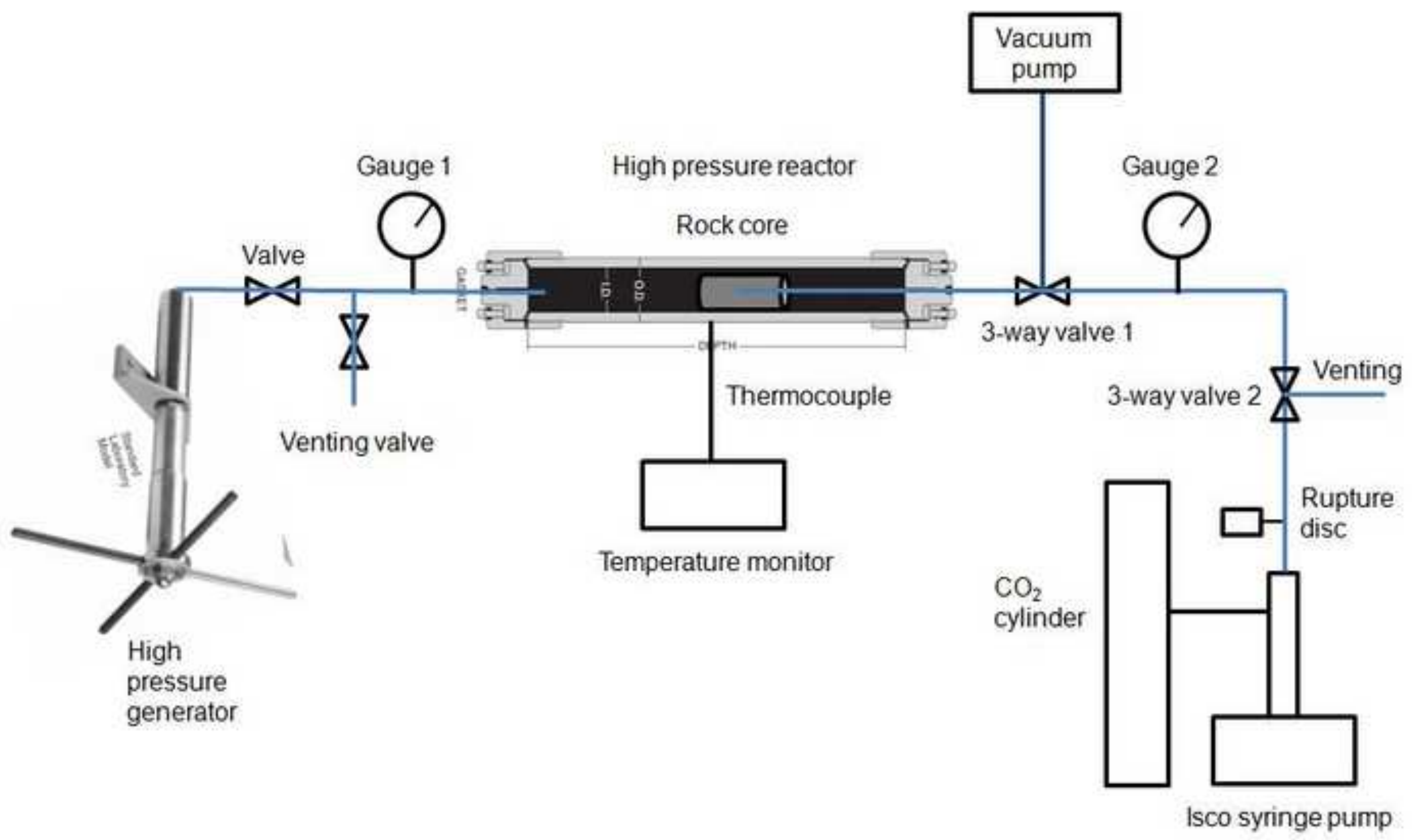


Figure 6

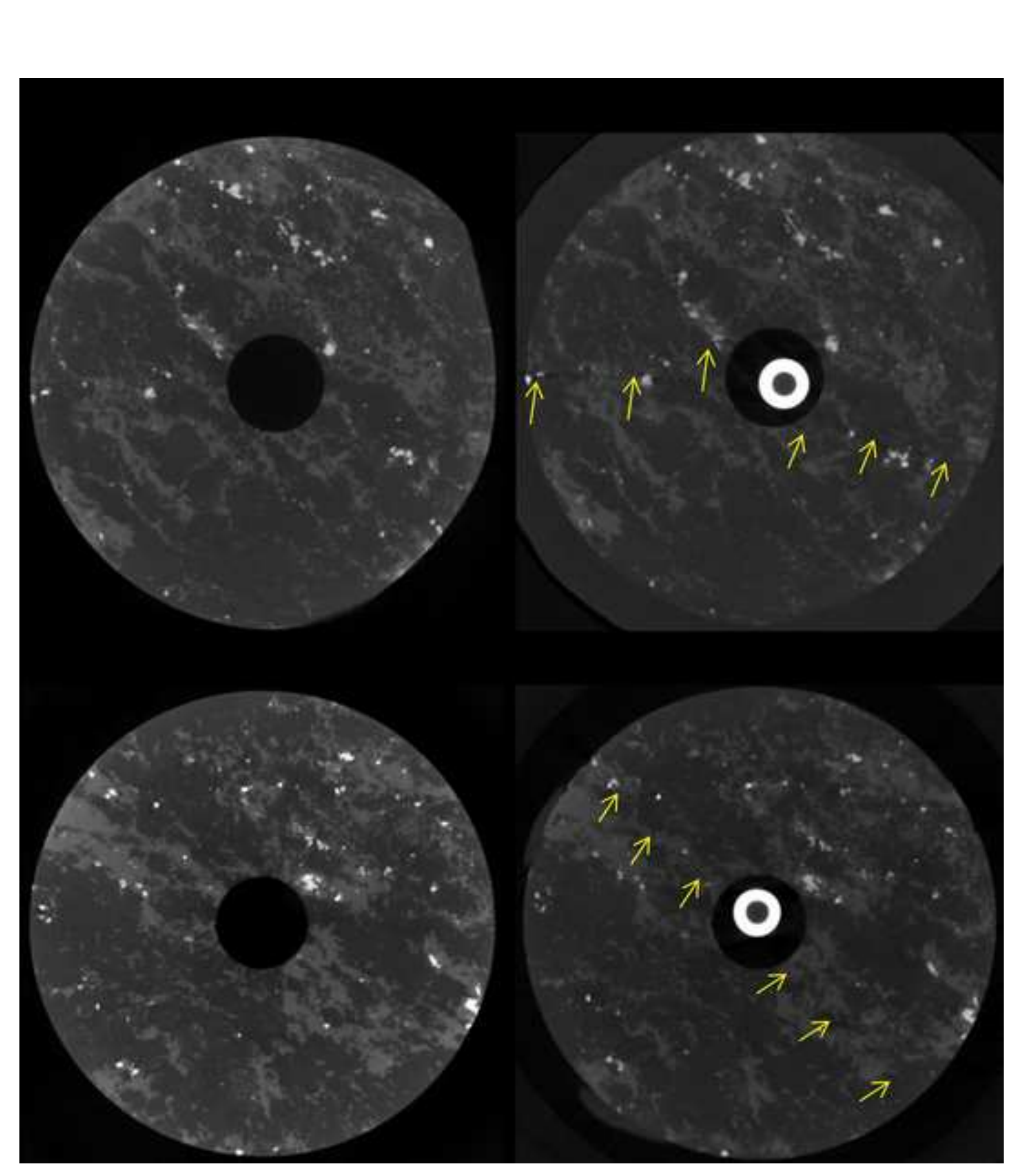

\author{
gure 6
}
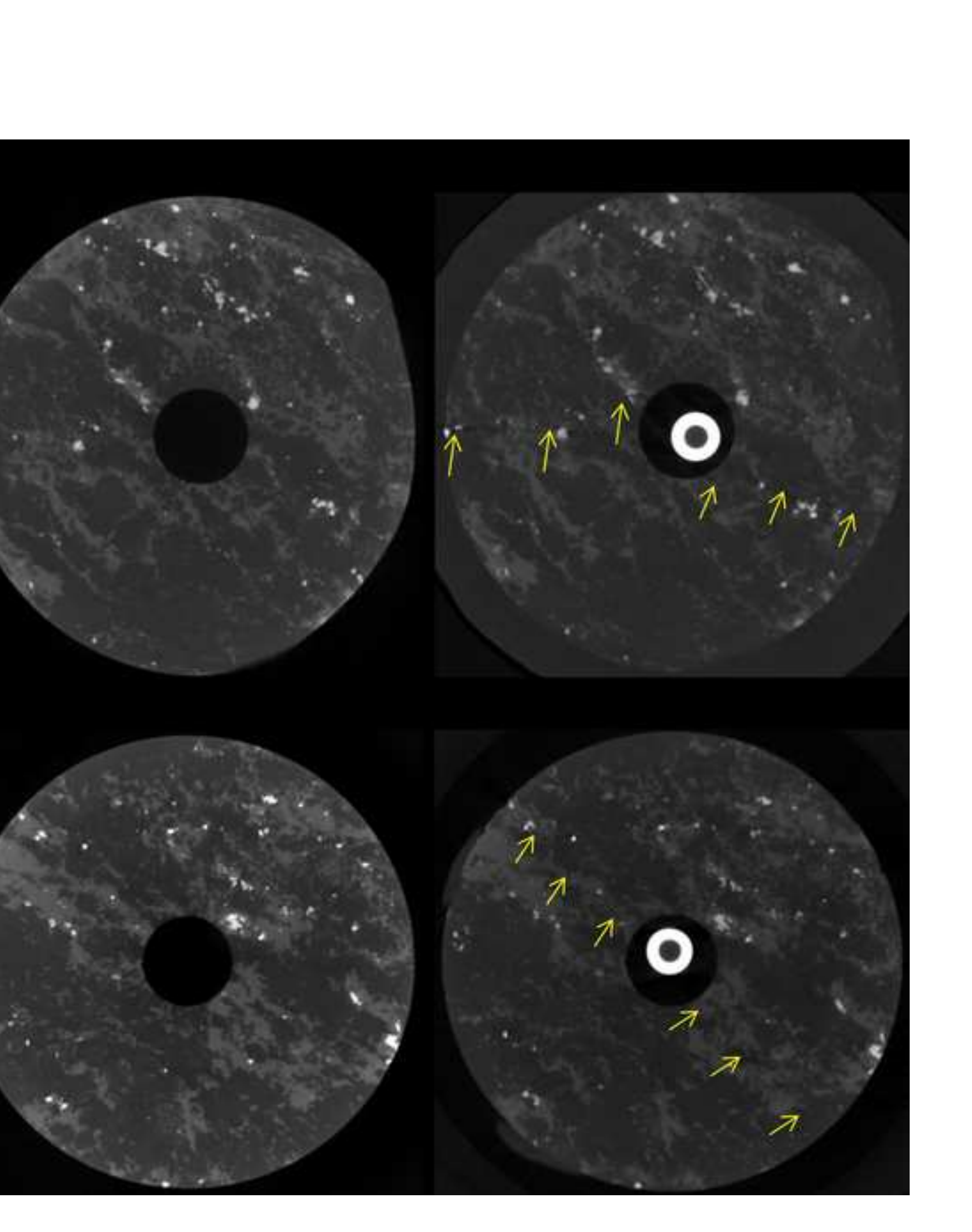

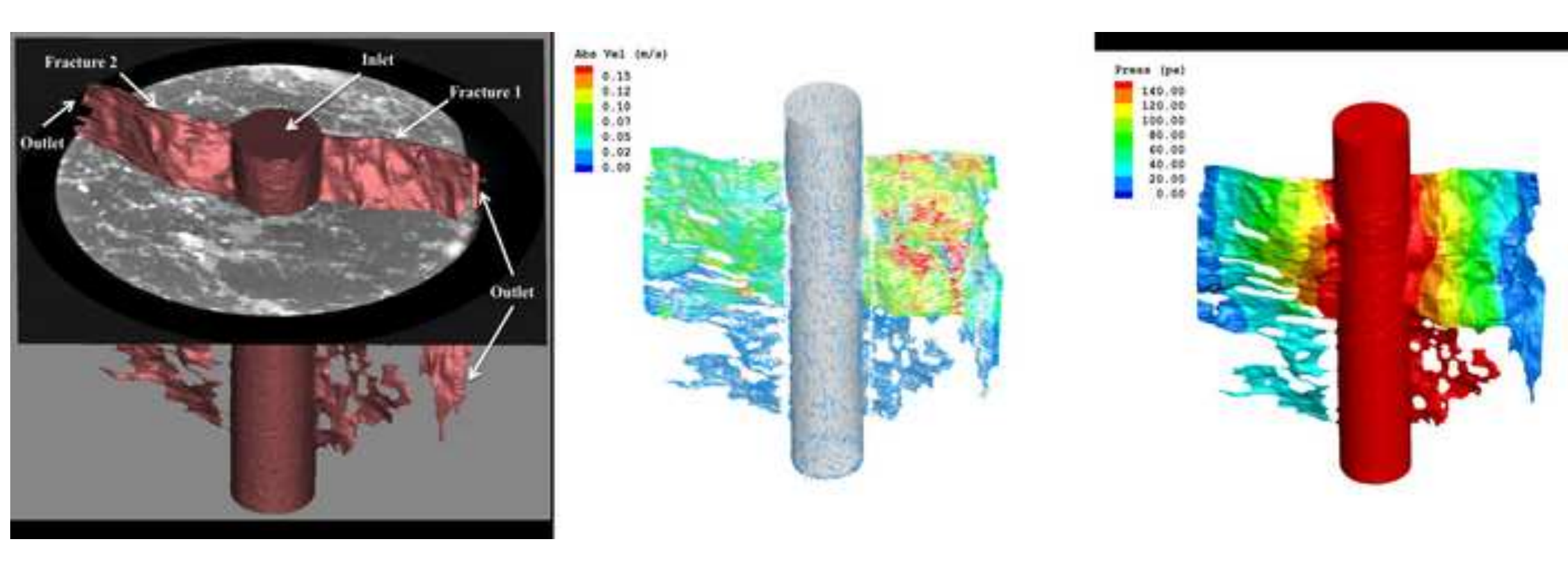

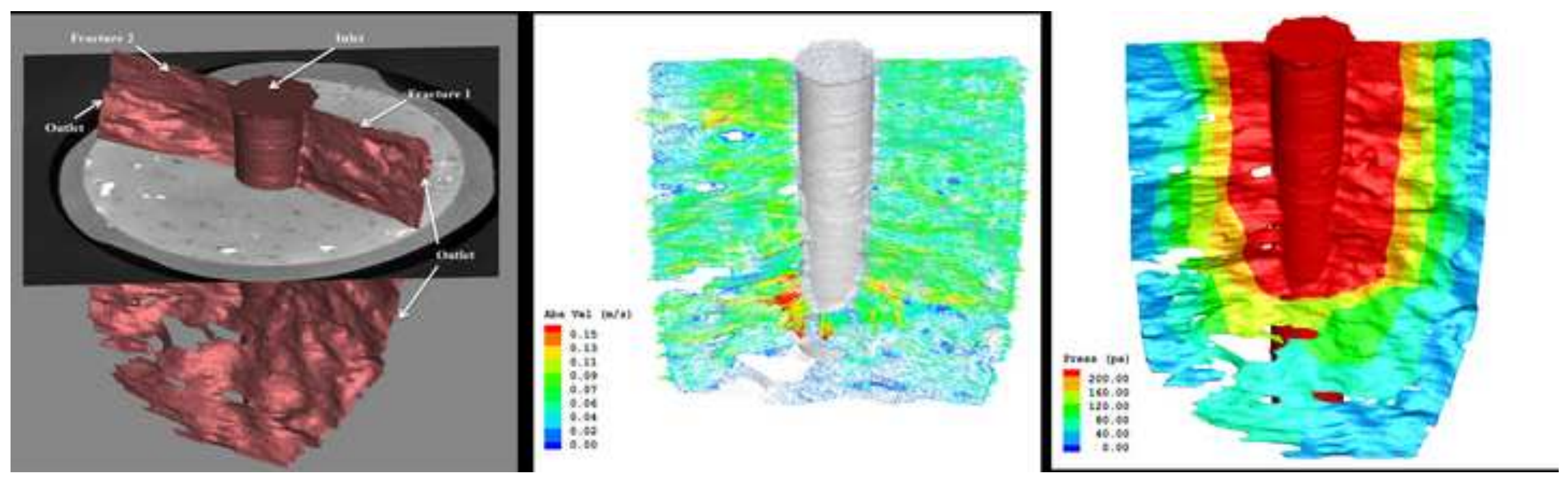